\title{
СОДЕРЖАНИЕ Т-2 И НТ-2 ТОКСИНОВ, АКТИВНОСТЬ ФЕРМЕНТОВ В КИШЕЧНИКЕ И ГЕМАТОЛОГИЧЕСКИЙ СТАТУС ЦЫПЛЯТ-БРОЙЛЕРОВ (Gallus gallus L.) ПРИ ЭКСПЕРИМЕНТАЛЬНОМ Т-2 ТОКСИКОЗЕ*
}

\author{
В.Г. ВЕРТИПРАХОВ, А.А. ГРОЗИНА, Н.Н. ГОГИНА, И.В. КИСЛОВА, \\ Н.В. ОВЧИННИКОВА, М.В. КОЩЕЕВА
}

В настоящее время описано более 400 микотоксинов. Все они обладают канцерогенными, мутагенными, тератогенными, эмбриотоксическими, аллергенными и иммуносупрессивными свойствами, подавляют клеточный и гуморальный иммунитет. В кормах птицы часто встречаются T-2 токсин и НТ-2 токсин, которые относятся к наиболее опасным трихотеценовым микотоксинам и вызывают гастроэнтериты, некроз кожи и слизистой оболочки ротовой полости, нарушение деятельности центральной нервной системы. Содержание Т-2 токсина в комбикормах для птиц регламентировано (ПДК = 100 мкг/кг, СанПиН 2.3.2.1078-01). Поражению органов под действием микотоксинов предшествуют функциональные нарушения, которые влияют на гематологический статус и ферментативные функции в пищеварительном канале. При исследовании этих функций наиболее точные результаты дают эксперименты in vivo на фистульных животных. В настоящей работе мы использовали этот подход в сочетании с анализом микотоксинов в лиофилизированных образцах химуса и помета методом высокоэффективной жидкостной хромато-масс-спектрометрии (ВЭЖХ-МС/МС) и показали, что при скармливании контаминированного Т-2 токсином комбикорма в кишечнике птицы обнаруживается Т-2 токсин в его метаболит - НТ-2 токсин, причем последний интенсивно всасывается в кровь и, видимо, переходит в ткани, поскольку его количество значительно снижается в помете по сравнению с дуоденумом. Целью работы было определение содержания Т-2 и НТ-2 токсинов в химусе и помете, активности пищеварительных ферментов и морфо-биохимических показателей крови цыплят-бройлеров кросса Смена 8 при экспериментальном Т-2 токсикозе. Птице в течение 2 нед скармливали корм, контаминированный Т-2 токсином в количестве от 100 мкг/кг (1ПДК) до 400 мкг/кг (4ПДК). Анализ химуса и помета показал, что в кишечнике цыплят-бройлеров Т-2 токсин трансформируется в метаболит - НТ-2 токсин. При этом последний имел тенденцию к интенсивному всасыванию в кровь. Потребление корма, содержащего Т-2 в количествах 100, 200 и 400 мкг/кг, привело к увеличению протеолитической активности дуоденального химуса на 46,3-96,6 \% (р < 0,05), активности липазы - на 16,8-25,5 \% (р < 0,05), амилазы - на 99,7 \% (при 4ПДК по Т-2 токсину). Активность щелочной фосфатазы снижалась на 23,8-27,9\% (p < 0,05). При этом в помете протеолитическая активность увеличивалась на 76,0-169,1 \% (р < 0,05), активность липазы снижалась на 23,2 \%(р < 0,05) (4ПДК по Т-2 токсину), амилазы - на 55,1-57,2 \% (p < 0,05). Биохимические исследования крови бройлеров показали снижение активности трипсина на $12,2-22,2 \%($ p $<0,05)$, увеличение активности щелочной фосфатазы (от $52,4 \%$ увеличения до 5-кратного). В результате фосфатазно-протеазный индекс увеличился в среднем с 31 до 92. В крови цыплят, получавших с кормом Т-2 токсин в дозе 0,4 мг/кг (4ПДК), содержание общего белка снизилось на 13,2 \% (р < 0,05), глюкозы - на 13,5\% $(\mathbf{p}<0,05)$, триглицеридов - в 4 раза. Вместе с тем наблюдалось снижение числа лейкоцитов в крови на 15,8-16,6 \%. В лейкоцитарной формуле наблюдалась тенденция увеличения лимфоцитов в опытных группах, получавших корм с Т-2 токсином в количестве 100 и 200 мкг/кг, в отличие от псевдоэозинофилов, что связано со специфической защитой организма при развитии микотоксикоза. Установлено, что образование метаболита НТ-2 из токсина Т-2 находится в обратной зависимости от активности трипсина в химусе кишечника и фосфатазно-протеазного индекса в крови бройлеров, что можно использовать на практике в качестве теста для диагностики Т-2 токсикоза.

Ключевые слова: Т-2 токсин, НТ-2 токсин, Т-2 токсикоз, бройлеры, химус, помет, пищеварительные ферменты, протеазы, липазы, амилазы, биохимия крови, трипсин, щелочная фосфатаза, триглицериды, морфология крови, лейкоцитарная формула.

В продуктах питания и кормах часто встречаются микотоксины вторичные метаболиты, продуцируемые видами несовершенных грибов (формальный класс Fungi imperfecti) родов Fusarium, Aspergillus, Myrothecium, Trichoderma, Trichothecium, Penicillium и др. Микотоксины различаются по

\footnotetext{
* Исследование выполнено при поддержке гранта Российского научного фонда для реализации научного проекта 20-76-10003 «Изучение действия Т-2 и НТ-2 токсинов на пищеварение у птиц, разработка методов диагностики и создание нового комплексного препарата для профилактики микотоксикозов». 
химическому строению, токсичности и механизму действия $(1,2)$. В настоящее время известно более 400 различных микотоксинов, наиболее распространенными и опасными для здоровья человека и животных считаются афлатоксины (афлатоксин В1), фумонизины, зеараленон, трихотецены типа В (дезоксиниваленол), трихотецены типа А (Т-2 токсин) и охратоксин А (3).

Трихотеценовые микотоксины синтезируются плесневыми грибами рода Fusarium, однако Cephalosporium, Myrothecium, Stachybotrys и Trichoderma также способны продуцировать эти соединения (4). Известно более 150 структурно родственных соединений, которые подразделены по химической структуре на 4 типа (от А до D) (5). Наиболее распространены и часто встречаются токсины группы А (НТ-2 и Т-2 токсины) и группы В (дезоксиниваленол - ДОН, 3-ацетилдезоксиниваленол, 15-ацетилдезоксиниваленол, ниваленол). Т-2 и НТ-2 токсины, хотя и представляют собой малочисленную группу, относятся к самыми токсичными представителями трихотеценовых микотоксинов (6). Указанные токсины способны привести к снижению прироста живой массы, геморрагическим поражениям слизистых оболочек, абортам, снижению молочной продуктивности и яйценоскости (7).

Мониторинговым исследованиям содержания микотоксинов в кормах во всем мире уделяется большое внимание. При этом наиболее контаминированным трихотеценовыми токсинами типа А сырьем признаны кукуруза (8), комбикорм (9) и ячмень (10). В климатических условиях Российской Федерации наиболее распространены трихотеценовые микотоксины типа А (Т-2 токсин и др.), трихотеценовые микотоксины типа В (ДОН и др.), зеараленон, охратоксин, фумонизины $(11,12)$.

Для промышленного птицеводства значительную угрозу представляет контаминация кормов Т-2 токсином, который негативно влияет на ряд физиологических функций птицы, что обусловлено его способностью ингибировать синтез белка, изменять экспрессию генов воспаления (13), что впоследствии приводит к некрозу и десквамации эпителиальных клеток слизистой оболочки железистого желудка (14). Поскольку Т-2 токсин имеет низкую биодоступность, большая его часть трансформируется в метаболиты, в частности в НТ-2 токсин (15).

Поступление больших количеств Т-2 и НТ-2 токсинов в организм животных приводит к снижению продуктивности, изменению биохимических показателей крови (16), структуры гепатоцитов (17), спленоцитов (18), сумки Фабрициуса (19). Существенный вред животноводству наносит аддитивная токсичность Т-2 токсина при наличии в кормах охратоксина А (20), фумонизина В и дезоксиниваленола (21), циклопиазоновой кислоты (22), афлатоксина (23).

Полнорационные комбикорма составляют основу кормления сельскохозяйственных животных. Согласно данным мониторинговых исследований кормов (24), Т-2 токсин распространен во всех регионах Российской Федерации. Наиболее часто (79,1 \% от исследованных проб) он встречается в комбикормах для птицы и свиней (25). Т-2 токсин также обнаружен в 32 \% проб пшеницы, 70,9 \% - ячменя, 94 \% - кукурузы (26), что следует учитывать при составлении полнорационных комбикормов. Иммуноферментный анализ контаминации микотоксинами комбикормов для птицы (27) показал, что в них присутствуют все основные группы микотоксинов, при этом Т-2 токсин был обнаружен в 88,2 \% исследованных проб.

Длительное время угрозу развития микотоксикозов оценивали на основании контроля безопасности кормов. Прямую и более информативную характеристику состояния животного при отравлении микотоксинами дает исследование биоматериалов - крови, мочи или кала (28). Метод высоко- 
эффективной жидкостной хромато-масс-спектрометрии (ВЭЖХ-МС/MC), который с высокой точностью позволяет определить микотоксины и их метаболиты в образцах крови, сердца, печени, селезенки, легких, почки, железистого желудка, мышечного желудка, тонкой кишки, мышц, костей, головного мозга (29).

У птицы вопросы патогенеза при потреблении контаминированных Т-2 и НТ-2 токсинами кормов остаются малоизученными, до настоящего времени не создано эффективных методов диагностики и средств профилактики этих микотоксикозов. Поражению органов под действием микотоксинов предшествуют функциональные нарушения, которые влияют на ферментативный статус пищеварительного канала и морфо-биохимические показатели крови. Попадая в организм, микотоксины подвергаются биохимическим превращениям. Наиболее полно проанализировать закономерности таких процессов позволяют опыты in vivo на фистульных животных с применением ВЭЖХ-МС/МС для определения микотоксинов в образцах.

В настоящей работе мы использовали такой подход и показали, что при скармливании контаминированного Т-2 токсином комбикорма в кишечнике птицы обнаруживается Т-2 токсин в его метаболит - НТ-2 токсин, причем последний интенсивно всасывается в кровь и, видимо, переходит в ткани, поскольку его количество значительно снижается в помете по сравнению с дуоденумом. Это сопровождается изменениями активности ферментов в дуоденальном химусе, ферментов крови и лейкоцитарной формулы, что свидетельствует о повышении токсической нагрузки на печень и развитии патологического процесса. В качестве маркера для ранней диагностики микотоксикозов мы предлагаем использовать фосфатазно-протеазный индекс, повышение которого в крови до значений более 20 ед. указывает на нарушение пищеварения (30).

Целью работы было определение содержания Т-2 и НТ-2 токсинов в химусе и помете, активности пищеварительных ферментов и морфо-биохимических показателей крови цыплят-бройлеров при экспериментальном Т-2 токсикозе.

Методика. Эксперименты проводили на цыплятах-бройлерах ( Gallus gallus L.) кросса Смена 8 в соответствии с требованиями Европейской конвенции о защите позвоночных животных, используемых для экспериментов или в иных научных целях (ETS № 123, Страсбург, 1986) (31). Вся птица с 1 - до 47-суточного возраста содержалась в условиях вивария (ФНЦ ВНИТИП РАН, 2020 год) с соблюдением режимов кормления и содержания в соответствии с требованиями для определенной возрастной группы и кросса птицы (32). Фистулирование 20 особей проводили в 20-25-суточном возрасте, канюлю вживляли напротив места впадения в кишечник панкреатических и желчных протоков по авторскому методу (33). В течение 1 сут после операции птицу не кормили, затем применяли нормированное кормление, следя за прохождением химуса в кишечнике. Швы снимали на 5-е сут. Из клинически здоровой птицы сформировали 4 группы по 5 гол. в каждой: I - контрольная, рацион без добавления Т-2 токсина, II - получающая рацион с добавлением Т-2 токсина на границе ПДК (100 мкг/кг), III - 2ПДК (200 мкг/кг), IV - 4ПДК (400 мкг/кг). Корм контаминировали Т-2 токсином до задаваемого уровня ПДК механическим способом с соблюдением требований безопасности персонала. Применяли стандартный Т-2 токсин (порошок с массовой долей основного вещества 99,7士0,3\%, «Romer Labs», Австрия, cat. N 10000310, LOT \#S17052T). Свежий корм задавали ежедневно, доступ к воде не ограничивали. 
Учетный подготовительный (фоновый) период длился с 26- до 33-суточного возраста птицы, период опыта - 14 сут (с 34- до 47-суточного возраста). Образцы дуоденального химуса и помет для определения содержания Т-2 и НТ-2 токсинов и ферментативной активности отбирали ежесуточно в течение всего эксперимента, включая подготовительный период, и помещали в морозильную камеру при температуре $-20{ }^{\circ} \mathrm{C}$. Из полученных образцов готовили объединенные пробы по каждому бройлеру (за подготовительный период и за каждую неделю эксперимента - к возрасту 40 и 47 сут) для последующей пробоподготовки и анализа (для определения Т-2 и НТ-2 токсинов дополнительно объединяли образцы от цыплят-бройлеров в каждой группе). Пробы химуса (1,0-2,0 мл) и помета (5,0 г) собирали ежесуточно в утренние часы, помещали в холодильную камеру при температуре $-20{ }^{\circ} \mathrm{C}$, образцы (по 5 г) высушивали в лиофильной сушилке серии TFD («ilShinBioBase Co., Ltd.», Южная Корея) в течение 34 ч при $-77,8{ }^{\circ} \mathrm{C}$ и давлении 5 mTorr (удаление $97 \%$ влаги из субстрата с сохранением биологически активных веществ). Кровь (2 мл) для исследования брали перед началом опыта и в конце каждой недели опыта (в возрасте птицы 33, 40 и 47 сут) из подкрыльцовой вены (cutanea ulnaris) на внутренней стороне крыла над локтевым сочленением. Место пункции на несколько минут зажимали стерильным тампоном. Образцы для биохимических исследований отбирали в стерильные вакуумные пробирки с литий-гепарином (объем 4,0 мл, «Shandong Weigao Group Medical Polymer Co., Ltd.», Китай), для морфологических - с антикоагулянтом K3-EDTA (объем 2,0 мл, «SOYAGREENTEC Co., Ltd.», Южная Корея). Для отделения плазмы от форменных элементов пробы центрифугировали при 5000 об/мин в течение 5 мин.

Пробы корма для анализа отбирали согласно ГОСТ 13496.0-2016 «Комбикорма, комбикормовое сырье. Методы отбора проб» (М., 2020) из мешков. Арбитражная проба готовилась из средней пробы массой 1 кг. Каждую пробу корма анализировали по 3 раза. Пробоподготовку осуществляли согласно ГОСТ 34140-2017 «Продукты пищевые, корма, продовольственное сырье. Метод определения микотоксинов с помощью высокоэффективной жидкостной хроматографии с масс-спектрометрическим детектированием» (М., 2020).

Количественное содержание Т-2 и НТ-2 токсинов в исходном комбикорме, дуоденальном химусе и помете измеряли (дважды в каждой анализируемой пробе) методом тандемной высокоэффективной жидкостной хромато-масс-спектрометрии (ВЭЖХ-МС/МС) (хроматографическая система Agilent 1260 Infinity, «Agilent Technologies», Германия, масс-спектрометр АВ SCIEX Triple Quad ${ }^{\mathrm{TM}}$ 5500, «Applied Biosystems», США; колонка Gemini® с обращенно-фазовым сорбентом на основе силикагеля с органическим полимером C18 $5 \mu \mathrm{m}$ 150×4,6 mm, «Phenomenex», США). Для построения калибровочных графиков и в качестве внутренних стандартов использовали стандартные растворы соответствующих микотоксинов (Т-2 и НТ-2 токсины) серии Biopure («Romer Labs», Австрия). При проведении анализов руководствовались ГОСТ 34140-2017. Использовали метанол, ацетонитрил (чистота ВЖХ-МС, массовая доля основного вещества не менее 99,9 \%) («Merk», Германия); ледяную уксусную кислоту, ацетат аммония (массовая доля основного вещества не менее 99,0 \%) («Sigma», Германия). Элюент A: $890 \mathrm{~cm}^{3}$ деионизированной воды, $100 \mathrm{~cm}^{3}$ метанола, $10 \mathrm{~cm}^{3}$ уксусной кислоты и 0,384 г ацетата аммония (5 ммоль/л). Элюент Б: $970 \mathrm{~cm}^{3}$ метанола, $20 \mathrm{~cm}^{3}$ деионизированной воды, $10 \mathrm{~cm}^{3}$ уксусной кислоты и 0,384 г ацетата аммония (5 ммоль/л). Раствор для экстракции - ацетонитрил:вода:уксусная 
кислота 79:20:1. Хроматографическое разделение проводили в режиме бинарного градиентного элюирования: 1,5 мин $100 \%$ элюэнта А, линейное увеличение доля элюента В до $50 \%$ в течение 1,5 мин, линейное увеличение доли элюента В до $100 \%$ в течение 9 мин. Время хроматографического разделения со $100 \%$ элюента В - 5 мин, последующее уравновешивание колонки -3 мин, $100 \%$ элюента А. Температура колонки $-25^{\circ} \mathrm{C}$; скорость подвижной фазы $-1 \mathrm{~cm}^{3}$ мин; температура ввода проб $-10{ }^{\circ} \mathrm{C}$, объем вводимой пробы 5 мм³ $^{3}$ Время удерживания для Т-2 токсина и НТ-2 токсина соответственно 10,30 и 9,79 мин; предел обнаружения для Т-2 токсина и НТ-2 токсина $-3,25$ и 2,70 мкг/кг, предел определения - 5,23-129,20 и 3,50-129,20 мкг/кг. Расчетный ион (в режиме положительной ионизации распылением в электрическом поле) для Т-2 токсина $-305,1 \mathrm{~m} / \mathrm{z}$, для НТ2 токсина $-345,1 \mathrm{~m} / \mathrm{z}$.

Амилазу определяли по Smith-Roy в модификации для высокой активности фермента (34), активность протеаз - по гидролизу казеина очищенного по Гаммерстену (калориметрический контроль при $\lambda=450$ нм), липазу - на полуавтоматическом биохимическом анализаторе SINNOWA BS-3000P («SINNOWA Medical Science \& Technology Co., Ltd», KHP) с набором ветеринарных диагностических реагентов («ДИАКОН-ВЕТ», Россия).

Биохимические исследования крови выполняли на полуавтоматическом биохимическом анализаторе BS-3000P (KHP) с набором для определения общего белка, щелочной фосфатазы, глюкозы, холестерина, триглицеридов, липазы («ДИАКОН-ВЕТ», Россия). Активность трипсина в плазме крови измеряли на полуавтоматическом биохимическом анализаторе BS3000Р (КНР) кинетическим методом (35) с использованием в качестве субстрата Na-бензоил-DL-аргинин-п-нитроанилид (BAPNA, «ACROS ORGANICS», Швейцария).

Морфологические исследования крови выполняли на автоматическом гематологическом анализаторе для ветеринарии DF-50 («Dymind Biotech», КНР) с применением фирменных реагентов.

Для статистической обработки результатов применяли программное обеспечение JMP Trial 14.1.0 (https://www.jmp.com/en_us/software/data-analysis-software.html). Результаты представлены в виде $M \pm \overline{\mathrm{SD}}$, где $M-$ среднее арифметическое, $\pm \mathrm{SD}$ - среднеквадратичное отклонение. Достоверность различий устанавливали по $t$-критерию Стьюдента, различия считали статистически значимыми при $\mathrm{p}<0,05$.

Результаты. Попадая в пищеварительный канал, микотоксины метаболизируются и в таком виде поступают в кровь. Известно, что в организме метаболизм Т-2 токсина происходит в реакциях деацетилирования, гидроксилирования и конъюгации $(2,16)$. Ранее мы показали (36), что у птиц Т-2 токсин превращается в НТ-2 токсин и существенно влияет на концентрацию оксида азота и активность панкреатических ферментов. В продолжение в настоящей работе данные химико-токсикологических и физиолого-биохимических исследований дополнены результатами общего и биохимического анализа крови в качестве клинических показателей статуса птицы при экспериментальном Т-2 токсикозе. Кроме того, нами была применена лиофильная сушка образцов для улучшения пробоподготовки.

Определение содержания Т-2 токсина и НТ-2 токсина в корме, дуоденальном химусе и помете контрольной фистулированной птицы (табл. 1) показало, что в корме до контаминации присутствовали Т-2 и НТ-2 токсины

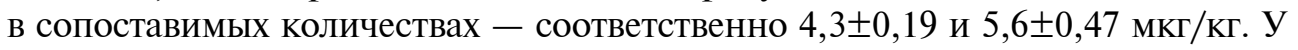
цыплят, получавших неконтаминированный рацион, эти токсины были найдены в химусе и помете в других соотношениях. В среднем за период 
эксперимента в контрольной группе в помете по сравнению с дуоденумом количество Т-2 токсина повышалось в 5 раз $(\mathrm{p}<0,05)$, что указывает на удаление из организма большей части токсина в неизменном виде. Однако содержание НТ-2 токсина в дуоденуме, превышающее в 6 раз таковое для Т-2 токсина, указывает на то, что в пищеварительном канале Т-2 токсин активно превращался в метаболит, способный всасываться в кровь. В помете мы наблюдаем такое же количество НТ-2 токсина, как и в дуоденальном химусе, за исключением IV группы. При увеличении количества T-2 токсина в корме до 100 мкг/кг корма (1ПДК) наблюдается резкое (в 40 раз) повышение содержания токсина в химусе по сравнению с контролем, однако в помете его выделение сохраняется на уровне контрольной пробы. Это можно объяснить переходом Т-2 токсина в НТ-2 форму с дальнейшим поступлением в кровь и ткани цыплят, поскольку уровень НТ-2 токсина в помете существенно не изменяется. Увеличение дозы токсина в корме до 200 мкг/кг сопровождалось повышением содержания Т-2 токсина в химусе в 2,4 раза $(\mathrm{p}<0,05)$, а в помете - в 2,1 раза по сравнению с 1ПДК. Содержание НТ-2 токсина увеличивалось соответственно на 20,9\% (p < 0,05) и на 20,8 \% (p > 0,05). Следовательно, соотношение Т-2 токсина и его метаболита в кишечнике и помете указывает на интенсивное всасывание НТ-2 токсина в кровь. При дозировке Т-2 токсина 400 мкг/кг его количество в помете увеличивалось по сравнению с контролем в 7,7 раза, что свидетельствует об адаптационных изменениях в кишечнике птицы, которые обеспечивают более интенсивное выведение токсина из кишечника, возможно, за счет более быстрого продвижения химуса в каудальном направлении. Клинически это проявляется расстройствами пищеварения и энтеритами с признаками диареи.

1. Концентрация микотоксинов (мкг/кг) в дуоденальном химусе и помете цыплят-бройлеров (Gallus gallus L.) кросса Смена 8 при экспериментальном T-2

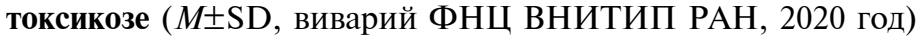

\begin{tabular}{|c|c|c|c|c|}
\hline \multirow[b]{2}{*}{ Микотоксин } & \multicolumn{4}{|c|}{ Группа $(n=5)$} \\
\hline & $\begin{array}{c}\text { I (контроль } \\
\text { без Т-2 токсина) }\end{array}$ & \begin{tabular}{|c|} 
II (Т-2 токсин \\
100 мкг/кг корма)
\end{tabular} & \begin{tabular}{|c|} 
III (Т-2 токсин \\
200 мКг/кг корма)
\end{tabular} & $\begin{array}{c}\text { IV (Т-2 токсин } \\
400 \text { мкг/кг корма) }\end{array}$ \\
\hline Т-2 токсин & $0,5 \pm 0,13$ & $\begin{array}{c}\text { Д у о д е н ал ь н } \\
20,2 \pm 2,75^{*}\end{array}$ & $\begin{array}{c}\text { ы й х и м у с } \\
49,6 \pm 6,00^{*}\end{array}$ & $41,9 \pm 6,36^{*}$ \\
\hline НТ-2 токсин & $30,0 \pm 4,90$ & $\begin{array}{r}47,9 \pm 1,60^{*} \\
\text { П о м }\end{array}$ & $57,9 \pm 3,20^{*}$ & $53,9 \pm 1,45^{*}$ \\
\hline $\begin{array}{l}\text { Т-2 токсин } \\
\text { НТ-2 токсин }\end{array}$ & $\begin{array}{r}2,5 \pm 0,26 \\
40,6 \pm 8,40\end{array}$ & $\begin{array}{r}2,3 \pm 0,40 \\
44,6 \pm 3,26\end{array}$ & $\begin{array}{c}4,8 \pm 0,68^{*} \\
53,9 \pm 3,60\end{array}$ & $\begin{array}{l}19,2 \pm 6,20^{*} \\
38,5 \pm 5,67\end{array}$ \\
\hline
\end{tabular}

П р и м е ч а н и е. В исходном корме (без контаминации) измеренное содержание Т-2 токсина составило 4,3 $\pm 0,19$ мкг/кг, НТ-2 токсина $-5,6 \pm 0,47$ мкг/кг. Образцы химуса и помета от каждого бройлера отбирали ежедневно в течение 14 сут опыта, объединяли в недельные пробы (возраст 40 и 47 сут; начало опыта с 34суточного возраста). По каждой группе из недельных проб формировали объединенные лиофилизированные пробы. Концентрации аналитов определяли методом тандемной высокоэффективной жидкостной хромато-масс-спектрометрии (ВЭЖХ-МС/МС) (каждое измерение выполнялось трижды, хроматографическая система Agilent 1260 Infinity, «Agilent Technologies», Германия, масс-спектрометр AB SCIEX Triple Quad ${ }^{\mathrm{TM}}$ 5500, «Applied Biosystems», США). Представлены средние (M) по недельным пробам по группам.

* Различия с контрольной группой статистически значимы при $\mathrm{p}<0,05$.

В нашем эксперименте, выполненном ранее, показано, что микотоксины в больших дозах оказывают отрицательное действие на активность пищеварительных ферментов (37). В продолжение исследований в настоящей работе мы определили активность пищеварительных ферментов в лиофилизированном дуоденальном содержимом и помете (табл. 2). Контаминация корма Т-2 токсином повлияла на протеолитическую активность дуоденального химуса, увеличивая ее во II группе на 78,9\% (p < 0,05), в III группе - на 46,3\% (p < 0,05), в IV - на 96,6 \% $(\mathrm{p}<0,05)$ по сравнению с подготовительным (фоновым) периодом. Повышение активности липазы во II и III группах были достоверны - соответственно на 25,5 и 
$16,8 \%(\mathrm{p}<0,05)$. Активность амилазы увеличивалась в IV группе на 99,7 \% $(\mathrm{p}<0,05)$. Активность щелочной фосфатазы в отличие от пищеварительных ферментов имела тенденцию снижаться (во II группе - на 23,8 \%, в III на $27,9 \%$ ) или не изменялась (в IV группе).

2. Активность пищеварительных ферментов в дуоденальном химусе и помете цыплят-бройлеров (Gallus gallus L.) кросса Смена 8 при экспериментальном T-2 токсикозе ( $M \pm \mathrm{SD}$, виварий ФНЦ ВНИТИП РАН, 2020 год)

\begin{tabular}{|c|c|c|c|c|c|c|}
\hline \multirow{3}{*}{ Показатель } & \multicolumn{6}{|c|}{ Группа $(n=5)$} \\
\hline & \multicolumn{2}{|c|}{$\begin{array}{c}\text { II (Т-2 токсин, } \\
100 \text { мкг/кГ корма) }\end{array}$} & \multicolumn{2}{|c|}{$\begin{array}{l}\text { III (Т-2 токсин, } \\
200 \text { мКг/кг корма) }\end{array}$} & \multicolumn{2}{|c|}{$\begin{array}{l}\text { IV (Т-2 токсин, } \\
400 \text { мкг/кГ корма) }\end{array}$} \\
\hline & $\begin{array}{l}\text { фоновый } \\
\text { период }\end{array}$ & опыт & $\begin{array}{l}\text { фоновый } \\
\text { период }\end{array}$ & опыт & $\begin{array}{l}\text { фоновый } \\
\text { период }\end{array}$ & опыт \\
\hline \multicolumn{7}{|c|}{ Дуоден альны й хи м ус } \\
\hline Амилаза, мг/(г·мин $)$ & $6433 \pm 446,0$ & $8100 \pm 861,2$ & $8550 \pm 1670,0$ & $5450 \pm 437,5$ & $5033 \pm 314,1$ & $10050 \pm 875,2 *$ \\
\hline Липаза, мкмоль/(г· мин $)$ & $29,4 \pm 2,59$ & $36,9 \pm 1,66^{*}$ & $25,6 \pm 0,49$ & $29,9 \pm 1,29^{*}$ & $22,0 \pm 3,43$ & $26,1 \pm 0,35$ \\
\hline Протеазы, мг/(г·мин $)$ & $190 \pm 18,7$ & $340 \pm 21,2 *$ & $229 \pm 22,8$ & $335 \pm 27,6^{*}$ & $233 \pm 13,5$ & $458 \pm 56,3^{*}$ \\
\hline Трипсин, мкмоль/(г· мин) & $4,92 \pm 0,364$ & $6,86 \pm 0,354$ & $5,27 \pm 0,581$ & $5,84 \pm 0,196$ & $6,47 \pm 0,589$ & $9,33 \pm 2,045$ \\
\hline $\begin{array}{l}\text { Щелочная фосфатаза, } \\
\text { мкмоль } /(\Gamma \cdot \text { мин })\end{array}$ & $147,5 \pm 13,64$ & $112,4 \pm 5,19 *$ & $134,6 \pm 1,88$ & $97,1 \pm 7,18^{*}$ & $140,0 \pm 2,11$ & $188,8 \pm 37,62$ \\
\hline $\begin{array}{l}\text { Фосфатазно-протеазный } \\
\text { индекс }\end{array}$ & 29,9 & 16,4 & 25,5 & 16,6 & 21,6 & 20,2 \\
\hline Амилаза, мг/(г・мин) & $1413 \pm 111,0$ & $635 \pm 67,1 *$ & $1890 \pm 275,1$ & $810 \pm 82,0^{*}$ & $1145+153,1$ & $1140 \pm 94.2$ \\
\hline Липаза, мкмоль/(г· мин $)$ & $1802 \pm 54,0$ & $1946 \pm 316,0$ & $913 \pm 6,6$ & $880 \pm 43,0$ & $1225 \pm 43,0$ & $941 \pm 33,0^{*}$ \\
\hline Протеазы, мг/(г·мин $)$ & $77 \pm 10,3$ & $182 \pm 22,1^{*}$ & $71 \pm 10,0$ & $125 \pm 6,5^{*}$ & $68 \pm 6,3$ & $183 \pm 4,6^{*}$ \\
\hline Трипсин, мкмоль/(г миин) & $4,38 \pm 0,349$ & $2,72 \pm 0,175$ & $3,79 \pm 0,233$ & $3,32 \pm 0,242$ & $3,39 \pm 0,313$ & $3,00 \pm 0,382$ \\
\hline $\begin{array}{l}\text { Щелочная фосфатаза, } \\
\text { мкмоль/(г· мин) } \\
\text { Фосфатазно-протеазный }\end{array}$ & $211,6 \pm 10,08$ & $140,8 \pm 30,98^{*}$ & $104,9 \pm 8,55$ & $77,5 \pm 4,92 *$ & $82,8 \pm 4,19$ & $143,1 \pm 14,08^{*}$ \\
\hline индекс & 48,3 & 51,8 & 31,6 & 23,3 & 24,2 & 47,7 \\
\hline $\begin{array}{l}\text { П р и м е ч а н и е. В исход } \\
4,3 \pm 0,19 \text { мкг } / \text { кг, НТ-2 токс } \\
\text { разцы химуса и помета от } \\
\text { до } 33 \text {-суточного возраста) } \\
\text { в опытный период, объеди } \\
\text { * Различия с подготовитель }\end{array}$ & $\begin{array}{l}\text { ном корме } \\
\text { сина }-5,6 \pm 0 \\
\text { каждого брой }\end{array}$ & $\begin{array}{l}\text { без контамина } \\
, 47 \text { мкг/кг. В } \\
\text { ілера отбирал } \\
4 \text { сут опыта (с } \\
\text { ьные пробы (Е } \\
\text { ым) периодом }\end{array}$ & $\begin{array}{l}\text { ации) измере } \\
\text { физиологич } \\
\text { и ежедневно } \\
34-\text { до } 47-c y \\
\text { возраст } 40 \text { и } \\
\text { с статистичес }\end{array}$ & $\begin{array}{l}\text { ое содерх } \\
\text { ом опыте }\end{array}$ & $\begin{array}{l}\text { ие Т-2 токси } \\
\text { гетод групп-г } \\
\text { та (фоновый } \\
\text { та), образцы }\end{array}$ & $\begin{array}{l}\text { ина составило } \\
\text { периодов) об- } \\
\text { период с 26- } \\
\text { I, полученные }\end{array}$ \\
\hline
\end{tabular}

Индивидуальные изменения активности протеаз, амилазы, трипсина и липазы в дуоденальном химусе цыплят-бройлеров, определяющие особенности их реакции на разные дозы Т-2 токсина в корме, представлены на сайте (http://www.agrobiology.ru, рис. 1). У большинства особей характерным ответом на введение в корм токсина было повышение активности протеолитических ферментов.

Биохимический анализ помета (см. табл. 2) выполняли после лиофильной сушки, полностью сохраняющей пищеварительные ферменты в активном состоянии. Результаты показали, что активность амилазы уменьшалась во II и III опытных группах соответственно на 55,1 и 57,2 \% по сравнению с фоновым периодом. Активность липазы снижалась при максимальной дозировке токсина на $23,2 \%$ (р < 0,05). Протеолитическая активность в помете значительно повышалась по мере увеличения дозы Т2 токсина в корме - соответственно на $136,4 \%, 76,0$ \% и 169,1 \% относительно фонового периода.

То есть активность протеаз в дуоденальном содержимом значительно превышает показатели в помете: во II группе в фоновый период в 2,5 раза, в опытный - в 1,9 раза; в III - соответственно в 3,2 и 2,7 раза, в IV - в 3,4 и 2,5 раза. Значительное снижение активности протеаз по мере продвижения по пищеварительному каналу можно объяснить возвращением ферментов в кровь согласно гипотезе о рекреции панкреатических ферментов $(38,39)$ либо их разрушением микрофлорой кишечника. Следует отметить стимулирующее действие микотоксинов на активность протеаз содержимого 12-перстной кишки. Кроме того, высокая протеолитическая активность со- 
храняется в помете птиц, что указывает на проявление признаков расстройства пищеварения, так как при усилении моторики кишечника происходит удаление избытка ферментов с пометом. Следовательно, при поступлении с кормом относительно небольших количеств токсина организм адаптируется и на первом этапе реагирует повышением протеолитической активности кишечных ферментов.

С учетом того, что активность протеаз кишечника коррелирует с активностью ферментов в крови, клинический тест на выявление Т-2 токсикоза может включать не только оценку протеолитической активности в экскрементах, но и изменение активности трипсина в плазме крови бройлеров (табл. 3).

3. Биохимические показатели крови у цыплят-бройлеров (Gallus gallus L.) кросса Смена 8 при экспериментальном T-2 токсикозе $(M \pm \mathrm{SD}$, виварий ФНЦ ВНИТИП РАН, 2020 год)

\begin{tabular}{|c|c|c|c|c|}
\hline \multirow[b]{2}{*}{ Показатель } & \multicolumn{4}{|c|}{ Группа $(n=5)$} \\
\hline & $\begin{array}{c}\text { I (контроль } \\
\text { без Т-2 токсина) }\end{array}$ & $\begin{array}{c}\text { II (Т-2 токсин, } \\
100 \text { мКг/кГ корма) }\end{array}$ & \begin{tabular}{|c|} 
III (Т-2 токсин, \\
200 мкГ/кГ корма)
\end{tabular} & $\begin{array}{c}\text { IV (T-2 токсин, } \\
400 \text { мкГ/кГ корма) }\end{array}$ \\
\hline \multirow{2}{*}{$\begin{array}{l}\text { Активность трипсина, } \\
\text { ед/л }\end{array}$} & $93,3 \pm 4,36$ & $\underline{81,9 \pm 1,58^{*}}$ & $\underline{82,5 \pm 1,12}$ & $\underline{72,6 \pm 0,31^{*}}$ \\
\hline & $\overline{77,5 \pm 6,43}$ & $\overline{68,6 \pm 3,02}$ & $60,4 \pm 3,89^{*}$ & $\overline{66,3 \pm 7,65}$ \\
\hline \multirow{2}{*}{$\begin{array}{l}\text { Активность щелочной } \\
\text { фосфатазы, ед/л }\end{array}$} & $\underline{4179 \pm 456,1}$ & $\underline{4310 \pm 609,7}$ & $\underline{4370 \pm 476,2}$ & $\underline{6369 \pm 757,8^{*}}$ \\
\hline & $\overline{1298 \pm 192,5}$ & $754 \pm 37,7$ & $\overline{1304 \pm 118,8}$ & $\underline{6487 \pm 570,5^{*}}$ \\
\hline Фосфатазно-протеазный & $\underline{45}$ & $\underline{53}$ & $\underline{53}$ & $\underline{87}$ \\
\hline \multirow[t]{2}{*}{ индекс } & $\overline{17}$ & $\overline{11}$ & $\overline{21}$ & $\overline{98}$ \\
\hline & $\underline{40,1 \pm 0,71}$ & $\underline{40,3 \pm 1,23}$ & $\underline{40,4 \pm 0,19}$ & $\underline{41,4 \pm 0,16}$ \\
\hline Общий белок, г/л & $\overline{36,3 \pm 1,20}$ & $\overline{36,4 \pm 0,13}$ & $\overline{35,5 \pm 0,21}$ & $\overline{40,1 \pm 0,85^{*}}$ \\
\hline \multirow{2}{*}{ Глюкоза, ммоль/л } & $\underline{12,4 \pm 0,24}$ & $\underline{11,3 \pm 0,33}$ & $\underline{12,9 \pm 0,07}$ & $13,0 \pm 0,21$ \\
\hline & $\overline{10,4 \pm 0,32} * *$ & $9,8 \pm 0,16 * *$ & $10,0 \pm 0,16^{* *}$ & $\overline{9,0 \pm 0,31} *, * *$ \\
\hline \multirow{2}{*}{ Триглицериды, ммоль/л } & $\underline{0,3 \pm 0,01}$ & $\underline{0,3 \pm 0,02}$ & $\underline{0,4 \pm 0,02}$ & $\underline{0,4 \pm 0,28}$ \\
\hline & $\overline{0,8 \pm 0,04} * *$ & $\overline{0,4 \pm 0,02}$ & $\overline{0,4 \pm 0,15}$ & $\overline{0,2 \pm 0,01}$ \\
\hline \multirow{2}{*}{ Холестерин, ммоль/л } & $\underline{3,4 \pm 0,04}$ & $\underline{3,1 \pm 0,05^{*}}$ & $\underline{3,6 \pm 0,25}$ & $\underline{3,6 \pm 0,21}$ \\
\hline & $2,8 \pm 0,14$ & $3,1 \pm 0,60$ & $3,1 \pm 0,26$ & $2,8 \pm 0,04 * *$ \\
\hline \multicolumn{5}{|c|}{$\begin{array}{l}\text { П р и м е ч а н и е. Над чертой - возраст бройлеров } 40 \text { сут, под чертой }-47 \text { сут. } \\
\text { * Различия с I (контрольной) группой статистически значимы при р }<0,05 . \\
\text { ** Различия между 47- и 40-суточными цыплятами статистически значимы при р }<0,05 .\end{array}$} \\
\hline
\end{tabular}

Согласно данным биохимических исследований крови, активность трипсина при экспериментальном Т-2 токсикозе снижалась с повышением дозы Т-2 токсина (наиболее заметно при 4ПДК) (см. табл. 3). Активность щелочной фосфатазы имела обратную динамику: при 4ПДК за 2 нед этот показатель возрастал в 5 раз с увеличением фосфатазно-протеазного индекса в среднем с 31 до 92 ед., что свидетельствует о снижении секреторной функции поджелудочной железы, уменьшении доступности питательных веществ и повышении токсической нагрузки на печень (40). При 4ПДК в крови цыплят содержание общего белка повысилось на 13,2 \%, но количество глюкозы снизилось на 13,5 \%, а триглицеридов в крови - в 4 раза, что указывает на наличие стрессовой реакции при поступлении Т-2 токсина с кормом.

Результаты выполненного нами исследования морфологических показателей крови цыплят отражают характер наблюдаемых гематологических отклонений при экспериментальном микотоксикозе (табл. 4). Число лейкоцитов значительно снизилось при 2ПДК Т-2 токсина в корме - на $15,8 \%$ у 40-суточных и на 16,6 \% у 47-суточных цыплят-бройлеров. Однако этот показатель оставался в пределах физиологической нормы, поэтому говорить о снижении иммунитета преждевременно. В лейкоцитарной формуле при 2ПДК и 4ПДК наблюдалась тенденция к увеличению числа лимфоцитов по сравнению с псевдоэозинофилами, что связано со специфической защитой организма при инфекционных и неинфекционных патологиях. Доля эозинофилов при 2ПДК снижалась, в остальных группах - повышалась по сравнению с контролем. Доля моноцитов при 1ПДК Т-2 токсина за первую 
неделю снижалась в 3 раза, затем стабилизировалась на одном уровне. При повышении дозы Т-2 токсина до 2ПДК снижение количества моноцитов было более выраженным (соответственно в 6 и 2 раза) по сравнению с контролем. Максимальная доза токсина (4ПДК) вызывала увеличение количества моноцитов в 1,5 раза в 40-суточном возрасте по сравнению с контрольной группой. Доля базофилов в лейкоцитарной формуле имела тенденцию к снижению в 47-суточном возрасте цыплят-бройлеров во II и III группах (в 2 раза по сравнению с контролем).

4. Лейкоциты крови и лейкоцитарная формула у цыплят-бройлеров (Gallus gallus L.) кросса Смена 8 при экспериментальном T-2 токсикозе $(M \pm S D$, виварий ФНЦ ВНИТИП РАН, 2020 год)

\begin{tabular}{|c|c|c|c|c|}
\hline \multirow[b]{2}{*}{ Показатель } & \multicolumn{4}{|c|}{ Группа $(n=5)$} \\
\hline & $\begin{array}{c}\text { I (контроль } \\
\text { без Т-2 токсина) }\end{array}$ & $\begin{array}{c}\text { II (Т-2 токсин, } \\
100 \text { мКг/кГ корма) }\end{array}$ & \begin{tabular}{|c} 
III (Т-2 токсин, \\
200 мкг/кГ корма)
\end{tabular} & $\begin{array}{c}\text { IV (T-2 токсин, } \\
400 \text { мкг/кГ корма) }\end{array}$ \\
\hline \multirow[t]{2}{*}{ Лейкоциты, $10^{9} / л$} & $\underline{32,2 \pm 0,90}$ & $\underline{27,1 \pm 0,61^{*}}$ & $\underline{29,6 \pm 0,70}$ & $\underline{32,7 \pm 1,65}$ \\
\hline & $\overline{30,8 \pm 1,25}$ & $\overline{25,7 \pm 0,23} *$ & $\overline{28,1 \pm 0,90}$ & $\overline{28,6 \pm 2,88}$ \\
\hline \multirow{2}{*}{$\begin{array}{l}\text { Псевдоэозино- } \\
\text { филы, \% }\end{array}$} & $\underline{44,8 \pm 1,49}$ & $\underline{33,9 \pm 1,95^{*}}$ & $\underline{36,0 \pm 1,23^{*}}$ & $\underline{47,8 \pm 3,05}$ \\
\hline & $\overline{41,1 \pm 2,46}$ & $\overline{34,2 \pm 0,98}$ & $\overline{45,2 \pm 6,24}$ & $\overline{36,6 \pm 1,70}$ \\
\hline \multirow[t]{2}{*}{ Лимфоциты, \% } & $\underline{48,8 \pm 1,70}$ & $\underline{62,3 \pm 2,24} *$ & $\underline{58,9 \pm 1,73^{*}}$ & $\underline{41,0 \pm 4,02}$ \\
\hline & $\overline{52,4 \pm 2,22}$ & $\overline{59,9 \pm 0,41}$ * & $\overline{47,7 \pm 7,56}$ & $\overline{55,2 \pm 0,29}$ \\
\hline \multirow[t]{2}{*}{ Моноциты, \% } & $\underline{0,6 \pm 0,08}$ & $\underline{0,2 \pm 0,03}^{*}$ & ${\underline{0,1 \pm 0,05^{*}}}^{*}$ & $\underline{0,9 \pm 0,05^{*}}$ \\
\hline & $\underline{0,4 \pm 0,07}$ & $0,3 \pm 0,10$ & $0,2 \pm 0,06$ & $0,5 \pm 0,09$ \\
\hline \multirow[t]{2}{*}{ Эозинофилы, \% } & $\underline{5,5 \pm 0,42}$ & $\underline{3,1 \pm 0,28^{*}}$ & $\underline{4,7 \pm 0,48}$ & $\underline{9,7 \pm 1,05^{*}}$ \\
\hline & $5,7 \pm 0,75$ & $5,3 \pm 0,50$ & $6,6 \pm 1,24$ & $7,2 \pm 1,36$ \\
\hline \multirow[t]{2}{*}{ Базофилы, \% } & $\underline{0,4 \pm 0,04}$ & $\underline{0,4 \pm 0,05}$ & $\underline{0,2 \pm 0,01} *$ & $\underline{0,4 \pm 0,03}$ \\
\hline & $\overline{0,4 \pm 0,06}$ & $\overline{0,2 \pm 0,03^{*}}$ & $0,2 \pm 0,03^{*}$ & $0,3 \pm 0,03$ \\
\hline $1 \mathrm{cos}$ & ад чертой - возр & $\begin{array}{l}\text { ройлеров } 40 \text { сут, } \\
\text { истически значим }\end{array}$ & $\begin{array}{l}\text { чертой }-47 \text { сут. } \\
\text { ри } \mathrm{p}<0,05 \text {. }\end{array}$ & \\
\hline
\end{tabular}

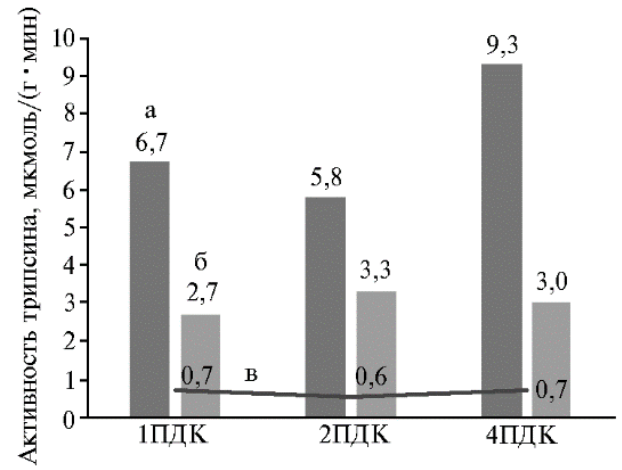

Рис. 2. Активность трипсина в разных биологических средах при экспериментальном Т-2 токсикозе цыплят-бройлеров (Gallus gallus L.) кросса Смена 8 (среднее за опыт для дозы токсина): а - дуоденальный химус, б помет, в - кровь; 1ПДК - 100 мкг/кг корма, 2ПДК - 200 мкг/кг корма, 4ПДК 400 мкг/кг корма (виварий ФНЦ ВНИТИП РАН, 2020 год).
Отмеченное нами увеличение количества НТ-2 токсина в химусе и помете цыплят-бройлеров при повышении дозы Т-2 токсина до 2ПДК (см. табл. 1) указывает на активный переход этого токсина из одной формы в другую. При этом количество Т-2 токсина в химусе 12-перстной кишки увеличилось в 2,5 раза, а НТ-2 токсина - в 1,2 раза по сравнению со II группой (1ПДК Т-2 токсина). Одновременно активность трипсина, который участвует не только в переваривании белков, но и в регуляции метаболизма (35), в 12-перстной кишке уменьшалась, а в помете - увеличивалась при незначительном изменении активности фермента в крови (рис. 2). Это указывает на защитную реакцию пищеварительных желез на действие токсина, которая проявляется в повышении секреции панкреатического и кишечного соков для сохранения энтерального гомеостаза при больших потерях жидкости организмом. В связи с увеличением скорости движения кишечного химуса при адаптации к воздействию токсина нарушается процесс возврата ферментов в кровь, и часть их выделяется вместе с пометом (36). При повышении дозы Т-2 токсина в корме бройлеров до 4ПДК отмечалось снижение количества Т-2 токсина в 
химусе 12-перстной кишки в 2,6 раза при 8,4-кратном увеличении в помете. Адаптация кишечника к Т-2 токсину в дозе 4ПДК имела существенные отличия от наблюдаемой при меньших дозах токсина: активность трипсина в дуоденальном химусе увеличивалась при практически постоянном содержании фермента в помете (см. рис. 2).

При сопоставлении метаболизации Т-2 токсина в НТ-2 токсин (соотношение количества НТ-2 токсина и Т-2 токсина) с изменением активности трипсина в химусе проявилась обратная зависимость между этими процессами, особенно при дозе Т-2 токсина 4ПДК (рис. 3). Также нами установлена обратная зависимость между фосфатазно-протеазным индексом крови и количественным соотношением НТ-2 токсин/Т-2 токсин в дуоденальном химусе при 4ПДК Т-2 токсина в корме, что может быть использовано при диагностике Т-2 микотоксикозов (см. рис. 3).

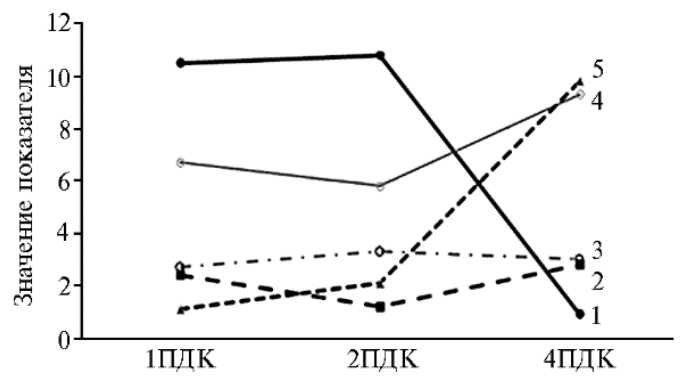

Рис. 3. Количественное соотношение НТ-2 токсин/Т-2 токсин в дуоденальном химусе (1) и помете (2), активность трипсина в помете, ед/м.л (3) и дуоденальном химусе, ед/мл (4) и фосфатазно-протеазный индекс крови (5) у цыплят-бройлеров (Gallus gallus L.) кросса Смена 8 при экспериментальном Т-2 токсикозе: 1ПДК - 100 мкг/кг корма, 2ПДК 200 мкг/кг корма, 4ПДК - 400 мкг/кг корма (виварий ФНЦ ВНИТИП РАН, 2020 год).

Таким образом, показано, что при экспериментальном Т-2 токсикозе в пищеварительном канале цыплят-бройлеров Т-2 токсин преобразуется в свой метаболит - НТ-2 токсин, причем последний интенсивно всасывается в кровь и переходит, видимо, в ткани, поскольку его количество значительно (на 28,7 \%) снижается в помете по сравнению с дуоденумом. При добавлении Т-2 токсина в корм (1ПДК, 2ПДК и 4ПДК - 100, 200 и 400 мкг/кг) протеолитическая активность в дуоденальном химусе возрастает соответственно на 78,9 \% (p < 0,05), 46,3 $\%(\mathrm{p}<0,05)$ и 96,6 \% (p < 0,05), то есть в наибольшей степени при 4ПДК. Здесь же отмечена максимальная активность амилазы (2-кратное увеличение). Повышение активность липазы (меньшее, но достоверное - на 25,5 и $16,8 \%$ при р < 0,05) происходило при скармливании 1ПДК и 2ПДК Т-2 токсина. Активность щелочной фосфатазы, наоборот, имела тенденцию снижаться (1ПДК и 2ПДК) либо не изменялась. В крови активность трипсина при экспериментальном Т-2 токсикозе снижалась на 12,2-22,2 \% (II, IV группы) в 40-суточном возрасте цыплят и на 22,1 \% (III группа) в 47суточном, а активность щелочной фосфатазы, наоборот, возрастала (5кратно за 2 нед при скармливании 4ПДК Т-2 токсина). Увеличение фосфатазно-протеазного индекса свидетельствовало о повышении токсической нагрузки на печень. Число лейкоцитов крови снижалось при 1ПДК в среднем на $16 \%$. В лейкоцитарной формуле отмечали тенденцию к увеличению доли лимфоцитов при нагрузке 1ПДК и 2ПДК в отличие от псевдоэозинофилов, что связано со специфической защитой организма от токсинов. Установлена обратная зависимость фосфатазно-протеазного индекса крови (ФПИ) от количественного соотношения НТ-2 и Т-2 токсинов в химусе при 4ПДК Т-2 токсина в корме. Выявлено повышение ФПИ при высоких дозах Т-2 токсина в корме. Определение ФПИ может служить тестом при диагностике Т-2 токсикозов птицы. 
141311 Россия, Московская обл., г. Сергиев Посад,

ул. Птицеградская, 10 ,

e-mail: Vertiprakhov63@mail.ru $\bowtie$, alena_fisinina@mail.ru,n.n.gogina@mail.ru,

irina.kislova1606198@yandex.ru, natalya.o90@mail.ru, vlk.733@mail.ru

\title{
THE INTESTINAL T-2 AND HT-2 TOXINS, INTESTINAL AND FECAL DIGESTIVE ENZYMES, MORPHOLOGICAL AND BIOCHEMICAL BLOOD INDICES IN BROILERS (Gallus gallus L.) WITH EXPERIMENTALLY INDUCED T-2 TOXICOSIS
}

\author{
V.G. Vertiprakhov ${ }^{凶}$, A.A. Grozina, N.N. Gogina, I.V. Kislova, N.V. Ovchinnikova, \\ M.V. Koshcheyeva
}

Federal Scientific Center All-Russian Research and Technological Poultry Institute RAS, 10, ul. Ptitsegradskaya, Sergiev Posad, Moscow Province, 141311 Russia, e-mail Vertiprakhov63@mail.ru ( $\square$ corresponding author), alena_fisinina@mail.ru,n.n.gogina@mail.ru, irina.kislova1606198@yandex.ru, natalya.090@mail.ru, vlk.733@mail.ru ORCID:

Vertiprakhov V.G. orcid.org/0000-0002-3240-7636 Grozina A.A. orcid.org/0000-0001-9654-7710

Gogina N.N. orcid.org/0000-0003-1937-286X

Kislova I.V. orcid.org/0000-0001-6399-6886

Ovchinnikova N.V. orcid.org/0000-0001-9877-2161

The authors declare no conflict of interests

Koshcheyeva M.V. orcid.org/0000-0002-0744-1883

Acknowledgements:

Supported financially by the Russian Science Foundation, grant No 20-76-10003 "The investigation of the effects of T-2 and NT-2 toxins on the digestive function in poultry, the development of methods of diagnostics and a new complex preparation for the prevention of mycotoxicoses"

Received April 22, 2021

doi: 10.15389/agrobiology.2021.4.682eng

\section{Abstract}

At present over 400 mycotoxins have been identified with mutagenic, teratogenic, embryotoxic, allergenic, and immunosuppressing properties, suppressing cellular and humoral immunity. Trichothecene mycotoxins are prevalent on the territory of Russian Federation, the most abundant and hazardous being T-2 and NT-2 toxins inducing gastroenterites, necroses of skin and mucosa of the oral cavity, disturbances in the function of central nervous system. The exposure limit for T-2 toxin in feeds for poultry is established in SanPiN 2.3.2.1078-1 at $100 \mu \mathrm{g} / \mathrm{kg}$. Mycotoxin induced injuries of the organs are preceded by functional disturbances affecting the hematological status and enzymatic reactions in the digestive tract; the most exact data on these disturbances can be obtained by in vivo experiments on fistulated birds. We used this approach in our study in combination with the analyses of mycotoxin concentrations in lyophilized samples of duodenal chyme and feces by high-performance liquid chromatography and tandem mass spectrometry (HPLC MS/MS). The aim of the study was the investigation of the T-2 toxin in the gastrointestinal tract and the effects of the toxin on the intestinal activities of the digestive enzymes and morphological and biochemical blood indices in cross Smena 8 broilers with experimentally induced T-2 toxicosis. Birds with chronic duodenal fistulae were fed the feeds contaminated with T-2 toxin in doses from $100 \mu \mathrm{g} / \mathrm{kg}$ (corresponding to the exposure limit statutorily set for chicken) to $400 \mu \mathrm{g} / \mathrm{kg}$ for 2 weeks. The measurements of the T2 toxin in the duodenal chyme and feces evidenced the transformation of T-2 to NT-2 toxin in the intestine and intense absorption of the latter into the bloodstream since its concentration in feces was significantly lower in compare to the duodenal chyme. All dietary doses of T-2 increased the duodenal activities of the total proteases (by 46.3-96.6\%, $\mathrm{p}<0.05$ ), lipase (by 16.8-25.5\%, $\mathrm{p}<0.05$ ), and amylase (by $99.7 \%$ ) at T-2 dose $400 \mu \mathrm{g} / \mathrm{kg}$ while activity of alkaline phosphatase decreased by $23.8-27.9 \%(\mathrm{p}<0.05)$. In the feces the increase in proteolytic activity by $76.0-169.1 \%(\mathrm{p}<0.05)$ and decreases in the activities of lipase (by $23.2 \%$ at T-2 dose $400 \mu \mathrm{g} / \mathrm{kg}$ ) and amylase (by 55.1-57.2 \%) were found. The activity of trypsin in blood serum decreased by $12.2-22.2 \%(\mathrm{p}<0.05)$ while the increases in the activity of alkaline phosphatase varied from $52.4 \%$ to 5 -fold. As a result the phosphatase-protease index increased from 31 to 92 in average. At T-2 dose $400 \mu \mathrm{g} / \mathrm{kg}$ the decreases in the concentrations in blood serum of total protein (by $13.2 \%, \mathrm{p}<0.05$ ), glucose (by $13.5 \%, \mathrm{p}<0.05$ ), and triglycerides (4-fold) were found. The total leukocyte number in blood decreased by 15.8-16.6\%. At T-2 doses 100 and $200 \mu \mathrm{g} / \mathrm{kg}$ the trend to higher percentage of the lymphocytes was found though the percentage of neutrophils remained unaffected, evidencing the activation of the specific antitoxic protective mechanisms. The inversed correlations between the degree of the transformation of T-2 toxin into NT-2 toxin and tryptic activity in duodenal chyme and phosphatase-protease index in blood serum were found; these correlations can be used in the diagnostic test for T-2 toxicosis. 
Keywords: T-2 toxin, NT-2 toxin, T-2 toxicosis, broilers, duodenal chime, digestive enzymes, proteases, lipase, amylase, biochemical blood indices, trypsin, alkaline phosphatase, triglycerides, cell blood composition, leukocytic formula.

\section{R E F E R E N C ES}

1. Awuchi C.G., Ondari E.N., Ogbonna C.U., Upadhyay A.K., Baran K., Okpala C.O.R., Korzeniowska M., Guiné R.P.F. Mycotoxins affecting animals, foods, humans, and plants: types, occurrence, toxicities, action mechanisms, prevention, and detoxification strategies - a revisit. Foods, 2021, 10(6): 1279 (doi: 10.3390/foods10061279).

2. Ivanov A.V., Fisinin V.I., Tremasov M.Ya., Papunidi K.Kh. Mikotoksikozy (biologicheskie i veterinarnye aspekty) [Mycotoxicosis (biological and veterinary aspects)]. Moscow, 2010 (in Russ.).

3. Hollander D., Croubels S., Lauwers M., Caekebeke N., Ringenier M., Meyer F.D., Reisinger N., Immerseel F.V., Dewulf J., Antonissen G. Biomonitoring of mycotoxins in blood serum and feed to assess exposure of broiler chickens. Journal of Applied Poultry Research, 2021, 30(1): 100111 (doi: 10.1016/j.japr.2020.10.010).

4. Pereira C.S., Cunha S.C., Fernandes J.O. Prevalent mycotoxins in animal feed: occurrence and analytical methods. Toxins (Basel), 2019, 11(5): 290 (doi: 10.3390/toxins11050290).

5. Marin S., Ramos A.J., Cano-Sancho G., Sanchis V. Mycotoxins: occurrence, toxicology, and exposure assessment. Food Chem. Toxicol., 2013, 60: 218-237 (doi: 10.1016/j.fct.2013.07.047).

6. Kovalsky P., Kos G., Nährer K., Schwab C., Jenkins T., Schatzmayr G., Sulyok M., Krska R. Co-occurrence of regulated, masked and emerging mycotoxins and secondary metabolites in finished feed and maize - an extensive survey. Toxins, 2016, 8: 363 (doi: 10.3390/toxins8120363).

7. Streit E., Schatzmayr G., Tassis P., Tzika E., Marin D., Taranu I., Tabuc C., Nicolau A., Aprodu I., Puel O., Oswald I. P. Current Situation of mycotoxin contamination and co-occurrence in animal feed-focus on Europe. Toxins (Basel), 2012, 4(10): 788-809 (doi: 10.3390/toxins4100788).

8. Biomin ${ }^{\circledR}$ mycotoxin prediction. Available: https://www.biomin.net/science-hub/. Accessed: 20.08.2021.

9. Labuda R., Parich A., Berthiller F., Tančinová D. Incidence of trichothecenes and zearalenone in poultry feed mixtures from Slovakia. Int. J. Food Microbiol., 2005, 105: 19-25 (doi: 10.1016/j.ijfoodmicro.2005.06.005).

10. Ibácez-Vea M., Lizarraga E., González-Peñas E., López de Cerain A. Co-occurrence of type-A and type-B trichothecenes in barley from a northern region of Spain. Food Control, 2012, 25: 8188 (doi: 10.1016/j.foodcont.2011.10.028).

11. Golovnya E.Ya., Lunegova I.V., Sviridova A.V. Mezhdunarodnyi vestnik veterinarii, 2016, 4: 6265 (in Russ.).

12. Dzhatdoeva A.A., Selimov R.N., Gracheva T.S., Metal'nikov P.S., Komarov A.A. Uspekhi meditsinskoi mikologii, 2018, 19: 297-298 (in Russ.).

13. Jing J.L., Zhang Y., Sun H., Wei J.T., Khalil M.M., Wang Y.W., Dai J.F., Zhang N.Y., Qi D.S., Sun L.H. The response of glandular gastric transcriptome to T-2 toxin in chicks. Food Chem. Toxicol., 2019, 132: 110658 (doi: 10.1016/j.fct.2019.110658).

14. Sun Y.X., Yao X., Shi S.N., Zhang G.J., Xu L.X., Liu Y.J., Fang B.H. Toxicokinetics of T-2 toxin and its major metabolites in broiler chickens after intravenous and oral administration. J. Vet. Pharmacol. Ther., 2015, 38(1): 80-85 (doi: 10.1111/jvp.12142).

15. Yang L., Tu D., Zhao Z., Cui J. Cytotoxicity and apoptosis induced by mixed mycotoxins (T-2 and HT-2 toxin) on primary hepatocytes of broilers in vitro. Toxicon, 2017, 129: 1-10 (doi: 10.1016/j.toxicon.2017.01.001).

16. Wan Q., He Q., Deng X., Hao F., Tang H., Wang Y. Systemic metabolic responses of broiler chickens and piglets to acute t-2 toxin intravenous exposure. J. Agric. Food Chem., 2016, 64(3): 714-723 (doi: 10.1021/acs.jafc.5b05076).

17. Yang L., Yu Z. Hou J., Deng Y., Zhou Z., Zhao Z., Cui J. Toxicity and oxidative stress induced by T-2 toxin and HT-2 toxin in broilers and broiler hepatocytes. Food Chem. Toxicol., 2016, 87: 128-137 (doi: 10.1016/j.fct.2015.12.003).

18. Chen Y., Han S., Wang Y., Li D., Zhao X., Zhu Q., Yin H. Oxidative stress and apoptotic changes in broiler chicken splenocytes exposed to t-2 toxin. BiomedReserch International, 2019, 25: 5493870 (doi: 10.1155/2019/5493870).

19. Lauwers M., De Baere S., Letor B., Rychlik M., Croubels S., Devreese M. Multi LC-MS/MS and LC-HRMS methods for determination of 24 mycotoxins including major phase I and II biomarker metabolites in biological matrices from pigs and broiler chickens. Toxins, 2019, 11(3): 171 (doi: 10.3390/toxins11030171).

20. Xue C.Y., Wang G.H., Chen F., Zhang X.B., Bi Y.Z., Cao Y.C. Immunopathological effects of ochratoxin A and T-2 toxin combination on broilers. Poultry Science, 2010. 89(6): 1162-1166 (doi: 10.3382/ps.2009-00609).

21. Kubena L.F., Edrington T.S., Harvey R.B., Buckley S.A., Phillips T.D., Rottinghaus G.E., Casper H.H. Individual and combined effects of fumonisin B1 present in Fusarium moniliforme culture 
material and T-2 toxin or deoxynivalenol in broiler chicks. Poultry Science, 1997, 76(9): 12391247 (doi: 10.1093/ps/76.9.1239).

22. Venkatesh P.K., Vairamuthu S., Balachandran C., Manohar B.M., Raj G.D. Induction of apoptosis by fungal culture materials containing cyclopiazonic acid and T-2 toxin in primary lymphoid organs of broiler chickens. Mycopathologia, 2005, 159(3): 393-400 (doi: 10.1007/s11046-0046271-x).

23. Huff W.E., Harvey R.B., Kubena L.F., Rottinghaus G.E. Toxic synergism between aflatoxin and T-2 toxin in broiler chickens. Poultry Science, 1988, 67(10): 1418-1423 (doi: 10.3382/ps.0671418).

24. Kononenko G.P., Burkin A.A. Fuzariotoksiny v zernovykh kormakh. Veterinarnaya patologiya, 2002 (2): 128-132 (in Russ.).

25. Kononenko G.P., Burkin A.A., Zotova E.V. Veterinariya segodnya, 2020, 32: 60-65 (doi: 10.29326/2304-196X-2020-1-32-60-65) (in Russ.).

26. Kononenko G.P., Burkin A.A., Zotova E.V. Veterinariya segodnya, 2020, 33: 139-145 (doi: 10.29326/2304-196X-2020-1-32-60-65) (in Russ.).

27. Grozina A.A., Gogina N.N., Kruglova L.M. Materialy XX Mezhdunarodnoi konferentsii. Rossiiskoe otdelenie Vsemirnoi nauchnoi assotsiatsii po ptitsevodstvu (VNAP RF) [Proc. XX Int. Conf. Russian branch of the World's Poultry Science Association (WPSA RF)]. Sergiev Posad, 2020: 211-213 (in Russ.).

28. Lauwers M., De Baere S., Letor B., Rychlik M., Croubels S., Devreese M. Multi LC-MS/MS and LC-HRMS methods for determination of 24 mycotoxins including major phase I and II biomarker metabolites in biological matrices from pigs and broiler chickens. Toxins, 2019, 11(3): 171 (doi: 10.3390/toxins11030171).

29. Yang L., Zhao Z., Wu A., Deng Y., Zhou Z., Zhang J., Hou J. Determination of trichothecenes A (T-2 toxin, HT-2 toxin, and diacetoxyscirpenol) in the tissues of broilers using liquid chromatography coupled to tandem mass spectrometry. J. Chromatogr. B Analyt. Technol. Biomed. Life Sci., 2013, 942-943: 88-97 (doi: 10.1016/j.jchromb.2013.10.034).

30. Vertiprakhov V.G., Grozina A.A., Kislova I.V. Sposob otsenki adaptatsii pishchevareniya ptitsy $k$ ingredientnomu sostavu ratsiona. Patent na izobretenie 2742175 C1, 02.02.2021. Zayavka № 2019142448 ot 19.12.2019 [Method for assessing the adaptation of poultry digestion to the ingredient composition of the diet. Patent 2742175 C1, 02.02.2021. Appl. № 2019142448 19.12.2019] (in Russ.).

31. European Convention for the Protection of Vertebrate Animals used for Experimental and other Scientific Purposes (ETS № 123) (Strasburg, 18.03.1986). Available: https://norecopa.no/legislation/council-of-europe-convention-ets-123. Accessed: 20.08.2021.

32. Borisenko K.V., Vertiprakhov V.G. Ptitsevodstvo, 2018, 10: 20-23 (in Russ.).

33. Rukovodstvo po optimizatsii retseptov kombikormov dlya sel'skokhozyaistvennoi ptitsy /Pod redaktsiei V.I. Fisinina [Optimized Poultry Compound Feed Recipes - Recommendations. V.I. Fisinin (ed.)]. Sergiev Posad, 2014: 3-4 (in Russ.).

34. Batoev Ts.Zh. Fiziologiya pishchevareniya ptits [Physiology of bird digestion]. Ulan-Ude, 2001 (in Russ.).

35. Vertiprakhov V.G., Grozina A.A. Veterinariya, 2018, 12: 51-54 (doi: 10.30896/00424846.2018.21.12.51-54) (in Russ.).

36. Vertiprakhov V.G., Titov V.Yu., Gogina N.N., Grozina A.A. Veterinariya, 2017, 10: 60-63 (in Russ.).

37. Vertiprakhov V.G., Gogina N.N., Grozina A.A., Khasanova L.V., Rebrakova T.M. Veterinariya $i$ kormlenie, 2017, 6: 17-20 (in Russ.).

38. Rothman S.S., Liebow C., Isenman L. Conservation of digestive enzymes. Physiological Review, 2002, 82(1): 1-18 (doi: 10.1152/physrev.00022.2001).

39. Korot'ko G.F. Rossiiskii zhurnal gastroenterologii, gepatologii, koloproktologii, 2011, 4: 14-21 (in Russ.).

40. Vertiprakhov V.G., Kislova I.V. Ptitsa i ptitseprodukty, 2020, 1:44-46 (doi: 10.30975/2073-49992020-22-1-44-46) (in Russ.). 